\title{
Long-term regional changes in inter-annual precipitation variability in the Campania Region, Southern Italy
}

\author{
Antonia Longobardi ${ }^{1} \cdot$ Ouafik Boulariah $^{1}$ (i)
}

Received: 23 September 2020 / Accepted: 4 February 2022 / Published online: 18 February 2022

(c) The Author(s) 2022

\begin{abstract}
Precipitation variability in space and time has been a focus of research over the past decades. The largest body of literature was essentially focused on long-term changes in average climates and in climate extremes. Analyses of the changes in the inter-annual climate variability (the year-to-year variability), which represent an index of climatic risk, received instead very less attention, but it represents an important issue in order to quantitatively measure the socioeconomic impact of climate change impact over water resources. In order to depict a general characterization of the long-term climate variability for the Campania region, located in Southern Italy within the Mediterranean basin, an analysis of the precipitation coefficient of variation, assumed as an index of inter-annual climate variability, was performed over the period 1918-2015 and compared with the annual precipitation regime and the intra-annual precipitation variability of the same region. The Mann-Kendall and the modified Mann-Kendall tests were applied to detect the sign and significance of the temporal changes and Sen's test was applied to quantify the temporal changes in inter-annual variability. The results illustrated a generalized condition (73\% of total stations) of statistically significant increase of inter-annual variability distributed almost over the whole analyzed area, even though the detected change appeared rather moderate in magnitude. The relationship between annual precipitation, intra-annual precipitation variability, and inter-annual precipitation variability was not clearly identified for the studied region, likely because of the characteristics of climatic homogeneity for the area under investigation. However, the comparative analyzes clearly showed how, if the variations in the annual precipitation regime and in the intra-annual precipitation variability are poorly significant (respectively for $9 \%$ and $11 \%$ of total station), changes in inter-annual precipitation variability are strongly marked over the studied region.
\end{abstract}

\section{Introduction}

Water scarcity is a recurring and worldwide phenomenon, with spatial and temporal characteristics that vary significantly from one region to another (Tallaksen and Van Lanen 2004). The climate change is likely to accelerate the climate-meteo-hydrological processes able to lead toward intense drought episodes (Longobardi and Van Loon 2018) and understanding historical precipitation variability is necessary to plan mitigation strategies to face future climate change impacts.

Ouafik Boulariah

oboulariah@unisa.it

Antonia Longobardi

alongobardi@unisa.it

1 Department of Civil Engineering, University of Salerno, Via Giovanni Paolo II, 123, 84084 Fisciano, SA, Italy
Precipitation variability in space and time has been a focus of research over the past decades indeed. The largest body of literature was essentially centered on long-term changes in average climates, such as monthly or annual scale precipitation and air temperature data (Rodriguez-Puebla et al. 1998; Martino et al. 2012; Santos et al. 2017). Also, temporal and spatial changes in climate extremes were intensively studied (Hamilton and Keim 2009; Sohoulande djebou and Singh 2016; He and Li 2019). Changes in average and extreme climates have an undoubted effect on water resources assessment, floods, and drought management, and affect plant growth, agricultural production, and the biogeochemical cycle. But, an equally important role is played by the interannual variability, in particular for what concerns the precipitation, which instead received very less attention. The interannual precipitation variability is intended as the year-to-year variability in cumulative precipitation occurrences and can represent an index of climatic risk, as long as it marks the possibility for a random sequence of years of rainfall abundance 
and years of rainfall scarcity, with their relevant consequences. In particular, for what concerns the socioeconomic impact of water resources management of complex systems under climate change scenarios, it was showed how including inter-annual precipitation variability leads towards more severe drought events and the largest water storage deficits (Preziosi et al. 2013; Pierleoni et al. 2014; Ronco et al. 2017).

In 1941, Conrad (1941) observed how "in some years on Malden Island, precipitation amounts to 100 millimeters and in others to 2.000 millimeters and more. The relative variability is 71 percent." On a global scale, using 384 rain gauge stations, he introduced the relative variability index and found that it decreased in general with an increase in mean annual precipitation (MAP). Over large areas, the relative variability however deviated significantly from the general global trend. Later, Nicholls and Wong (1990) used the coefficient of variation $(\mathrm{CV})$ as a measure of precipitation inter-annual variability and found very similar results. Fatichi et al. (2012) demonstrated, in a global scale study, how the MAP only explains the $16 \%$ of the CV variations and that an additional index which describe the intra-annual variability, the PCI (precipitation concentration index; Oliver (Oliver 1980) could help improve the interpretation of the inter-annual precipitation variability.

Most of the studies related to inter-annual variability involved future predictions of $\mathrm{CV}$ values and temporal patterns under climate change scenarios conventionally proposed by the IPCC. The analyzed scale was overall a global scale and the general trend predicted an increase in inter-annual variability (Giorgi and Bi 2005; Giorgi and Lionello 2008; Pendergrass et al. 2017; He and Li 2019). But, water shortage can vary significantly from one region to another (Tallaksen and Van Lanen 2004), and investigating precipitation interannual variability at this scale is also very important especially to quantitatively measure the socioeconomic impact of climate change over these particular systems. Regional-scale analyses are however seldom find in the current specific literature. Only two studies over a tropical climate region and one in a Mediterranean climate-type region analyzed CV temporal patterns derived from historical precipitation time series, confirming an increase in the CV (Gajbhiye et al. 2016; He and Gautam 2016; Chandniha et al. 2017). Another limitation is represented by the massive use of projected climate change scenario from where potentially infer the climatological characteristics of a specific area. Coarse spatial resolution data from global weather dataset or climate models are indeed poorly effective because of the high precipitation variability that affects particular regions of the globe; thus, historical in situ measurement are crucial for reliable drought conditions assessment (Marini et al. 2019). Especially for what concerns the Mediterranean basin, it is well known to be featured by a large climate variability (Luterbacher et al. (2006)) and was recognized as one of the most outstanding "Hot-Spots" in the future climate change predictions (Giorgi (2006)). Numerous studies involving Mediterranean long-term precipitation showed a moderate to a strong reduction in precipitation over the last 50 years (Dünkeloh and Jacobeit 2003; Ramos and Martínez-Casasnovas 2006; Longobardi and Villani 2010; Meddi et al. 2010; Boulariah et al. 2017; Lazoglou et al. 2019). The large decrease in average precipitation is coupled to an increase in precipitation variability, especially during the warm season, as illustrated by Giorgi (2006). Using the $\mathrm{CV}$ as a measure of precipitation variability, he developed a regional climate change index RCCI, using 20 global climate models, concluding that the Mediterranean, along with the North-Eastern European regions, emerges as the most responsive region to climate change.

In the outlined context of scarcity of empirical regionalscale studies based on historical observations, the current work aims to illustrate the results in terms of inter-annual precipitation variability for a specific area, located in the Mediterranean basin. The study area is a $25,000 \mathrm{~km}^{2}$ region located in Southern Italy and was already analyzed in the past for a climatological characterization (Longobardi and Villani 2010; Califano et al. 2015; Longobardi and Mautone 2015; Longobardi et al. 2016; Fattoruso et al. 2017; Longobardi et al. 2021). The annual precipitation in the region appeared to show a general negative trend, which was however statistically significant for only a limited number of rain gauge stations. Changes in intra-annual precipitation variability, summarized by the PCI index, were also evaluated, showing a general trend for a precipitation regime shift from a seasonal to a more uniform one, but again the statistical significance was limited to a small number of rain gauge stations.

In the current research, the $\mathrm{CV}$ average and spatial variability at the regional scale were first illustrated. Thirty years moving windows $\mathrm{CV}$ time series were then reconstructed for each station, in order to analyze the temporal changes in the CV patterns. The Mann-Kendall and the Mann-Kendall modified test for autocorrelated time series were used to measure the statistical significance and the sign of the changes (Hamed and Rao 1998; Yue and Wang 2004), and Sen's slope test was adopted to measure the magnitude of temporal changes in CV (Theil 1950; Sen 1968). In the end, the inter-annual precipitation changes were compared with the previously studied annual precipitation regime and intra-annual precipitation variability changes, in order to depict a general characterization of the long-term climate variability for the investigated region.

\section{Materials and methods}

\subsection{Study area and available data set}

The region under investigation is a large area of about $25,000 \mathrm{~km}^{2}$, located in Southern Italy, stretching from the 
Apennine Mountains to the Mediterranean Sea with a progressively decreasing elevations moving from the inlands to the coastline (Fig. 1). The climate regime of the study area is typically seasonal with some evident differences depending on the location of the station. Large precipitation is recorded during the winter periods and near or in correspondence with the tallest reliefs, because of the significant orographic effect on precipitation.

The rain gauge network for the investigated region was managed by the SIMN Servizio Idrografico e Mareografico Nazionale for the period 1918-1999. Available data consist of annual and monthly precipitation time series for over 300 sites located across the Campania region and the Lazio region. A data quality control process was performed in Longobardi and Villani (2010) and only 163 rain gauge stations were successfully at a time series homogeneity statistical analysis.

After 1999, the Regional Civil Protection Department was charged for rain gauge network reorganization and management. A change in the consistency, spatial location, and typology of rain gauge stations occurred around that period indeed, which undermined the possibility for a database merging. In fact, only a subset of 30 stations were found to share the same location in both database and moreover showed statistical homogeneity features over the period 1918-2015 (Longobardi et al. 2016). For the remaining stations, the change in the gauge location, in particular, prevented the possibility to reconstruct a long precipitation time series by the two database merging. Finer time scale resolution precipitation at $10 \mathrm{~min}$ was available from 2000 to 2015, which were aggregated at the monthly scale for the purpose of comparison with the data recorded by the former meteorological service.

With the aim to illustrate, on the one hand, the longterm variability over the longest available period and, on the other, the broadest spatial patterns variability, the current analysis was performed in two subsequent steps. At first, in order to represent the spatial variability at the regional scale, the investigation was focused on the 163 stations for which available data span 1918-1999. Secondly, the 30 stations subset was investigated in order to represent the temporal variability over the longest available period. Comparison of the results referred to the period 1918-1999 and 1918-2015 was also performed.

Daily, monthly, and annual time series are available for the period 1918-2015. The current analysis is focused on the annual scale.

\subsection{Inter-annual variability index computation}

The average $\mathrm{CV}$ for each rain gauge station was computed as the ratio between the annual precipitation standard deviation $\sigma$ and mean annual precipitation $\mu$ :

$$
C V=\frac{\sigma}{\mu}
$$

Fig. 1 Case study digital elevation model and rain gauge stations location

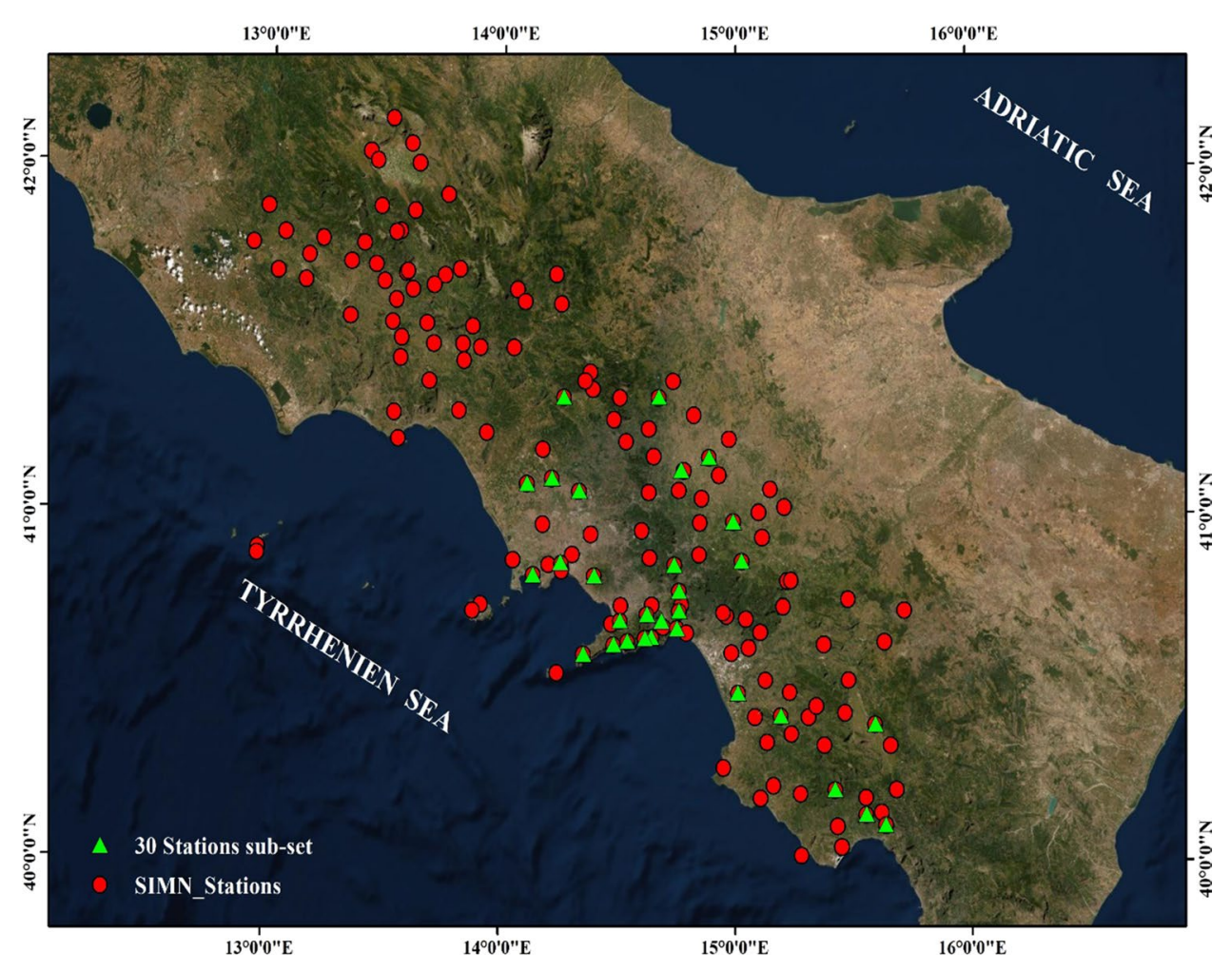


It represents an average index of inter-annual variability. In order to detect changes in the inter-annual variability precipitation time series, the CV, as defined by Eq. (1), has also been computed on a 30-year moving window. In this way, the $\mathrm{CV}$ time series was reconstructed for each rain gauge station, to be further tested for significance and magnitude of the temporal trends. A 30-year period has been chosen as a compromise between the definition of a climate normal WMO (1989) and the average temporal extension of the available historical observation.

\subsection{Trend detection analysis}

Time series of $\mathrm{CV}$ was tested for trend detection in time. A trend is a significant change over time exhibited by a random variable, detectable by statistical parametric and non-parametric procedures. In particular, the current study provided and compared results for non-parametric Mann-Kendall (MK), modified Mann-Kendall (MMK), and Sen's tests approaches.

The Mann-Kendall test (Mann 1945; Kendall 1948) is one of the most widely used methods to detect a trend in climatology analysis. It is used to analyze data collected over time for consistently increasing or decreasing trends (monotonic). It is a non-parametric test, which means it works for all distributions; thus, tested data does not have to meet the assumption of normality but should have no serial correlation.

To take account of the presence of both positive and negative autocorrelation in analyzed data, which might increase the probability to detect trends when actually none exists, the modified Mann-Kendall test can be applied (Hamed and Rao 1998), where the effective sample size is considered in order to modify the Mann-Kendall statistic.
The Sen estimator (Sen 1968) is a method for robustly fitting a line to sample points by choosing the median of the slopes of all lines through pairs of points. Compared to the non-robust simple linear regression (least squares), it can be significantly more accurate for skewed and heteroskedastic data and competes well against least squares even for normally distributed data in terms of statistical power.

\section{Results}

\subsection{Average CVs for the period 1918-1999}

The average $\mathrm{CV}$ empirical distribution is represented by the boxplot in Fig. 2. The minimum and maximum $\mathrm{CV}$ values found for the case study, respectively $14.37 \%$ and $35.16 \%$, appear higher than the extremes of the CV range found by Gajbhiye et al. (2016) and Chandniha et al. (2017) in a tropical climate area, confirming the largest variability which characterizes the Mediterranean basin. The median value is about $20.88 \%$. The interquartile range, which represents an index of dispersion in the data, amounts to only $4.12 \%$. Few outliers skew the data ( 8 rain gauge stations) being only above the boxplot upper fence. They all correspond to average CV values larger than $29.29 \%$.

The spatial pattern of the average $\mathrm{CV}$ of the investigated area was estimated through the application of an ordinary kriging geostatistical interpolation and is represented in Fig. 2. There do not seem to be well-organized spatial patterns of average CVs. However, the higher average CV values appear to be located in the extreme areas of the studied region that is in the southern and northern sections. A central area between these two sections and the entire inland
Fig. 2 Spatial distribution of average $\mathrm{CV}$ over the studied region

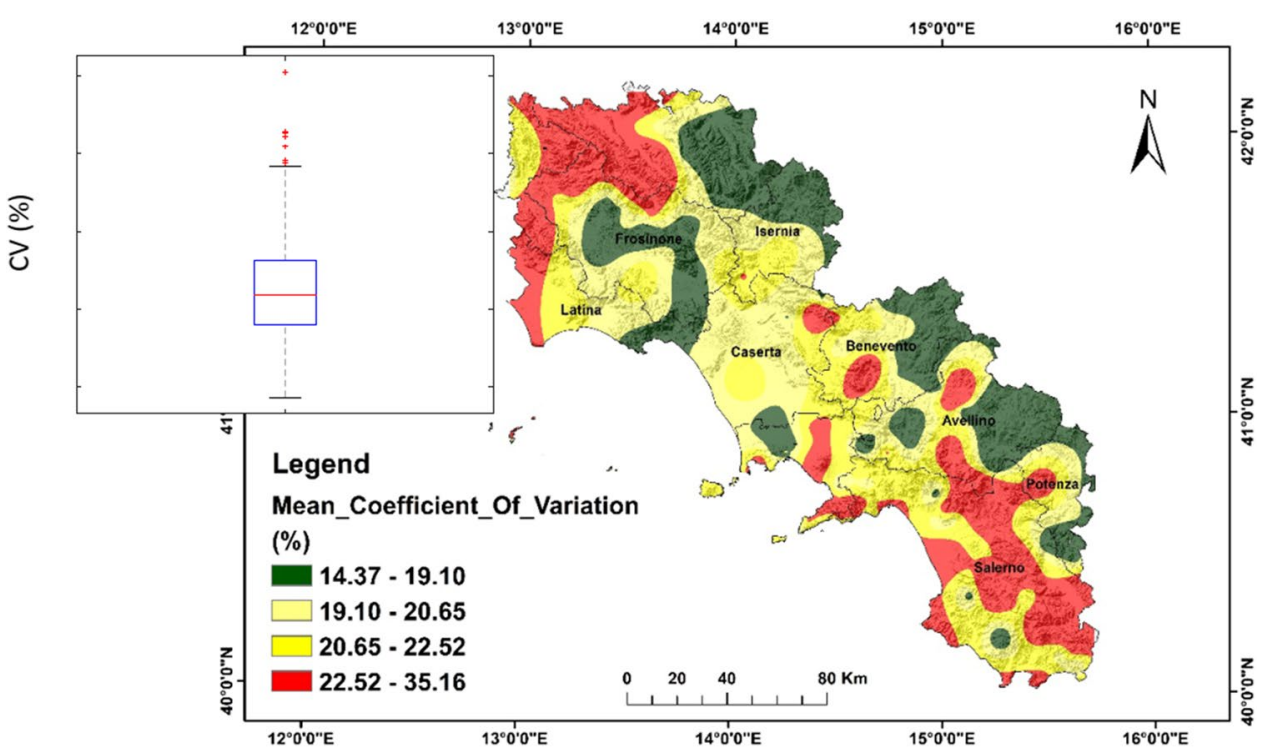


area is instead characterized by lower values of the average CV.

\subsection{CV temporal patterns for the period 1918-1999}

For what concerns the temporal patterns of the 30-years moving window $\mathrm{CVs}$, each rain gauge station clear exhibits a different pattern, but they can be basically grouped into four different typologies as depicted in Fig. 3. Beyond an increasing (e.g., ID 3610) and a decreasing (e.g., ID 3768) monotonic behavior, a number of stations also presented complex patterns, where either a stationary condition (e.g., ID 3623) or a decreasing trend (e.g., ID 3747) precedes an increase in the CV trend that generally occurs during the 1970s.

The relevant results of the Mann-Kendall (MK) and of the Modified Mann-Kendall (MMK) test for trend sign and significance (significance level $\alpha=5 \%$ ) are illustrated in Table 1.
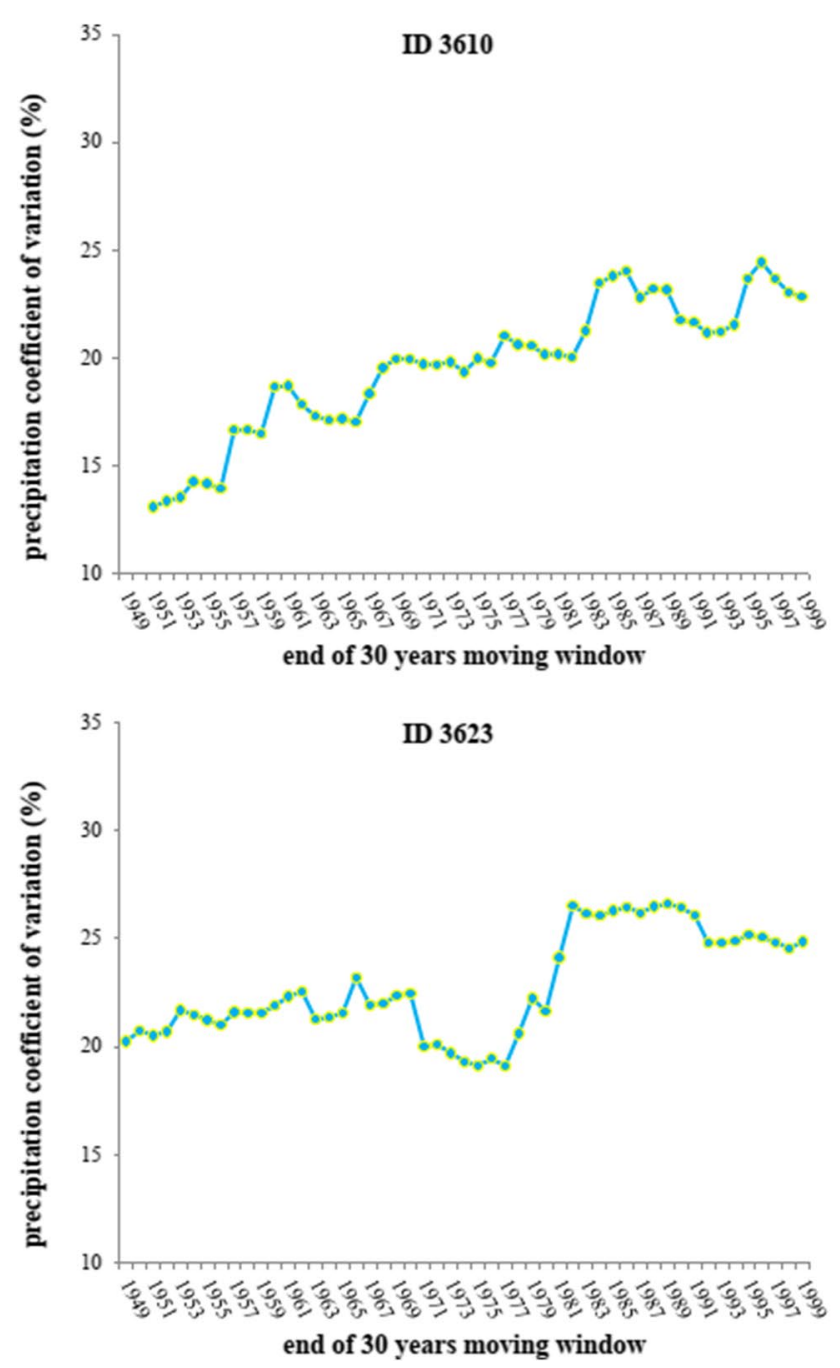

Both MK and MMK illustrate how a very large fraction, respectively $80 \%$ and $73 \%$, of the rain gauge stations show a significant trend. The MMK test actually detects a lower number of stations exhibiting a significant trend, pointing out the potential effect of the autocorrelation in the data which is not taken into account by the MK. However, the difference in the number of the stations that present a significant trend between the MK and MMK test does not appear

Table 1 Results for the Mann-Kendall (MK) and modified MannKendall (MMK) tests $(\alpha=5 \%)$

\begin{tabular}{lll}
\hline & MK \% & MMK \% \\
\hline Stations with significant trend & 80 & 73 \\
Stations with not significant trend & 20 & 27 \\
Stations with positive trend & 70 & 72 \\
Stations with negative trend & 30 & 28 \\
\hline
\end{tabular}
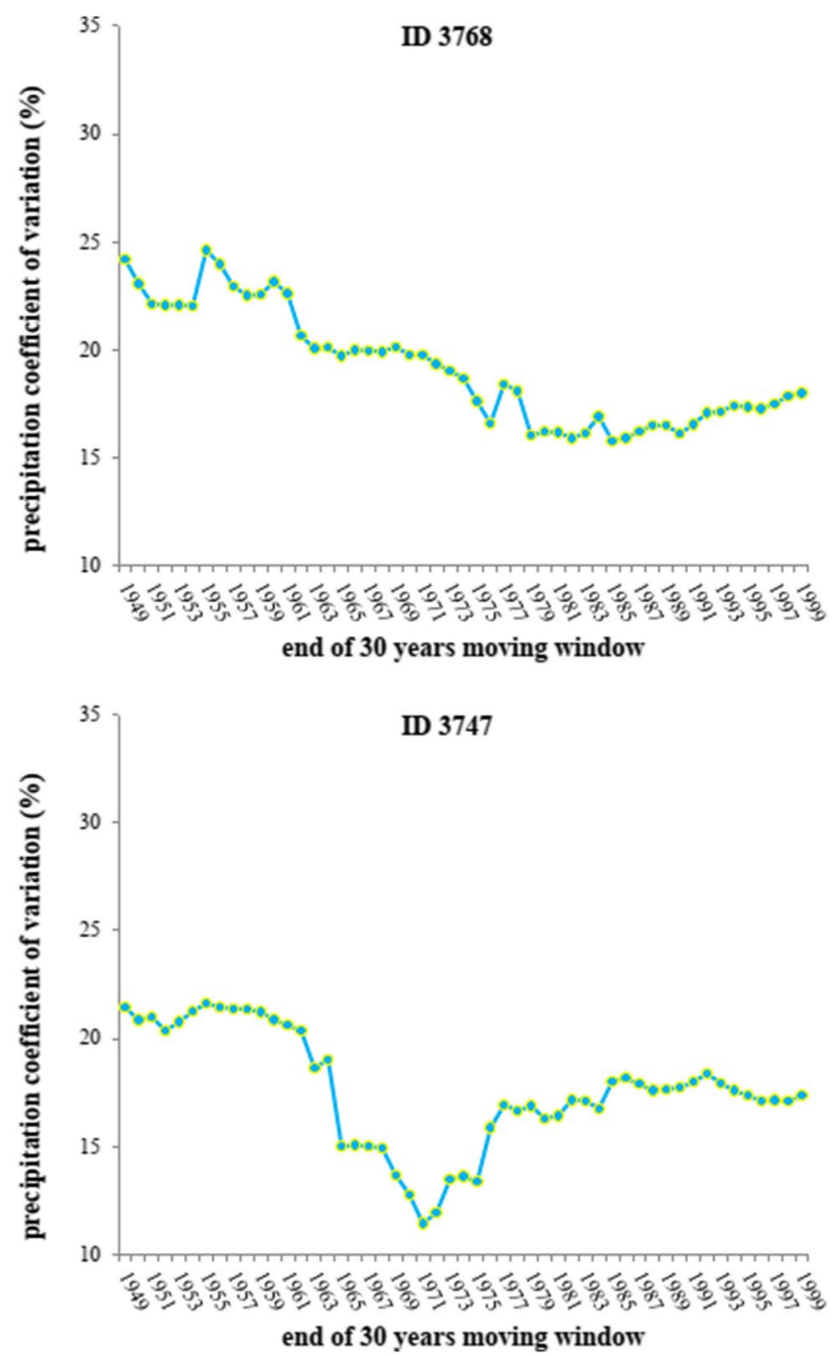

Fig. 3 Typical CVs pattern over the studied region. ID = rain gauge station code 
relevant, as it only amounts to $8 \%$ of total stations. For what concerns the spatial variability, the results of the MMK test are further discussed in the following.

Figure 4 (left panel) illustrates the spatial distribution of the rain gauge stations with a significant/not significant trend, provided by an ordinary kriging geostatistical interpolation. As already commented, the rain gauge stations that exhibit a significant trend are dominant in the case study, and additionally, their spatial distribution is strongly uniform.

For what concerns the sign of the trend, according to MMK tests, a very large fraction of about $72 \%$ of the rain gauge stations shows a positive trend. Negative trends appear to dominate the southern area of the region, even though not markedly (Fig. 4 (right panel)). Positive trends dominate instead the remaining part. The overall findings of the MMK test are indeed generalized conditions of significant increase of inter-annual variability almost over the whole analyzed area.

Figure 5 illustrates Sen's slope magnitude over the studied region $(\alpha=5 \%)$. The slope is expressed as the percentage of annual increase or decrease in CV over the whole observations recording period. The empirical distribution of Sen's slope values is represented by the boxplot in Fig. 5. The minimum and maximum $\mathrm{CV}$ values found for the case study amount respectively to $-0.36 \%$ and $0.55 \%$. The median value is about $0.06 \%$. The interquartile range, which represents an index of dispersion in the data, amounts to only $0.19 \%$. Only two outliers skew the data, being one above the $0.35 \%$ boxplot upper fence and the other below the $0.23 \%$ boxplot lower fence. Beyond the overall generalized conditions of significant increase of inter-annual variability almost over the whole analyzed area as described by the results of the MMK test, the results of Sen's test depict a rather moderate magnitude of the detected changes.

As in the case of the average CV spatial distribution, there do not seem to be well-organized spatial patterns of the magnitude of changes in CV. Visually comparing Figs. 2 and 5, areas featured by the lowest decrease in CV seem to relate to areas where the largest average values of CV have been detected. In this respect, rain gauge stations featured by the largest average inter-annual variability seemed to be the less affected by temporal changes.

\subsection{CV temporal patterns for the period 1918-2015 and comparison with the period 1918-1999}

As previously mentioned, only a subset of 30 stations was investigated for the period 1918-2015 because of data availability (the stations share the same location in both datasets)
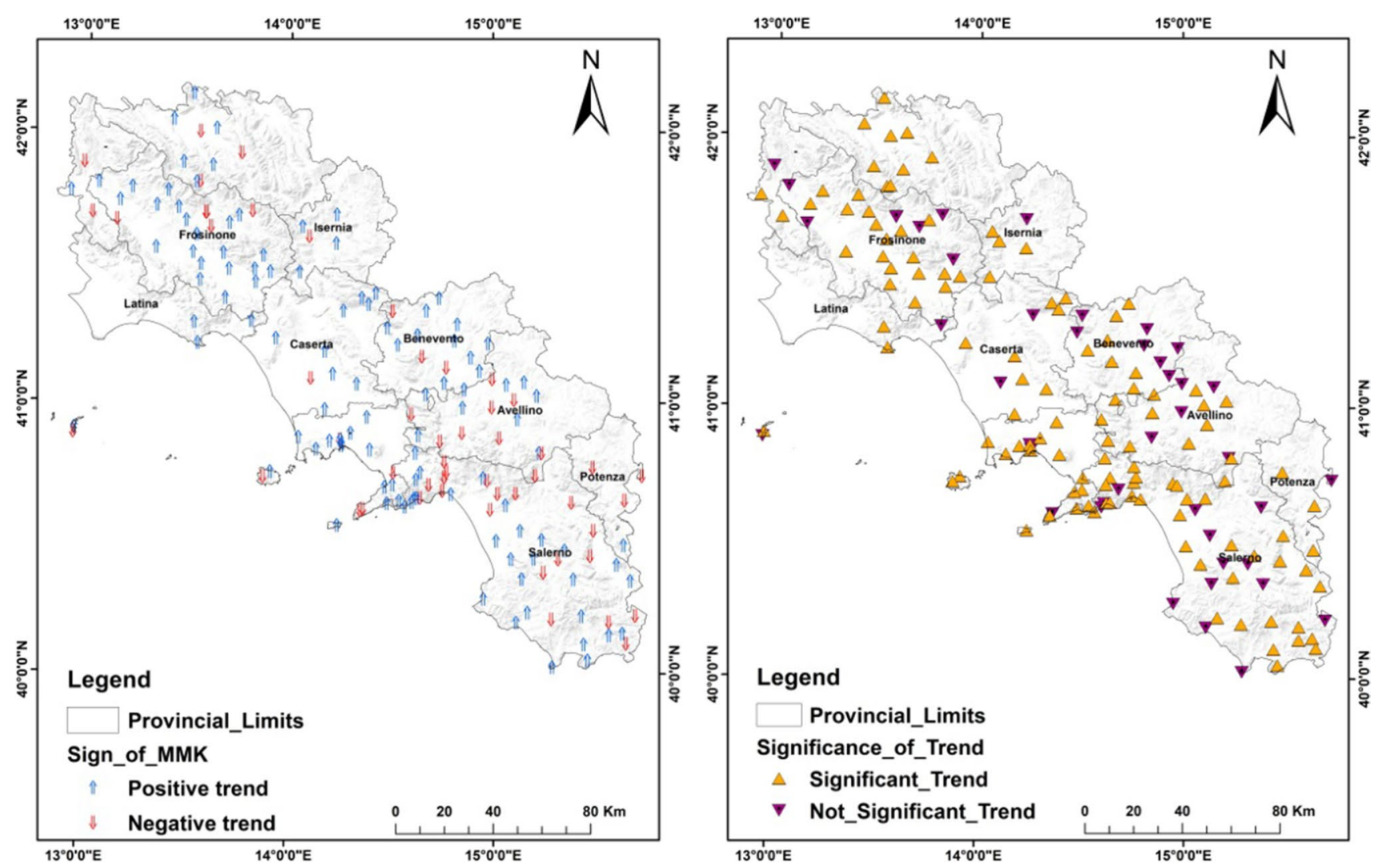

Fig. 4 MMK significance (left panel) and sign (right panel) over the studied region ( $\alpha=5 \%)$ 
Fig. 5 CV Sen's slope trend magnitude over the studied region $(\alpha=5 \%)$. The slope is expressed as the percentage of annual increase or decrease in $\mathrm{CV}$ over the whole observations recording period

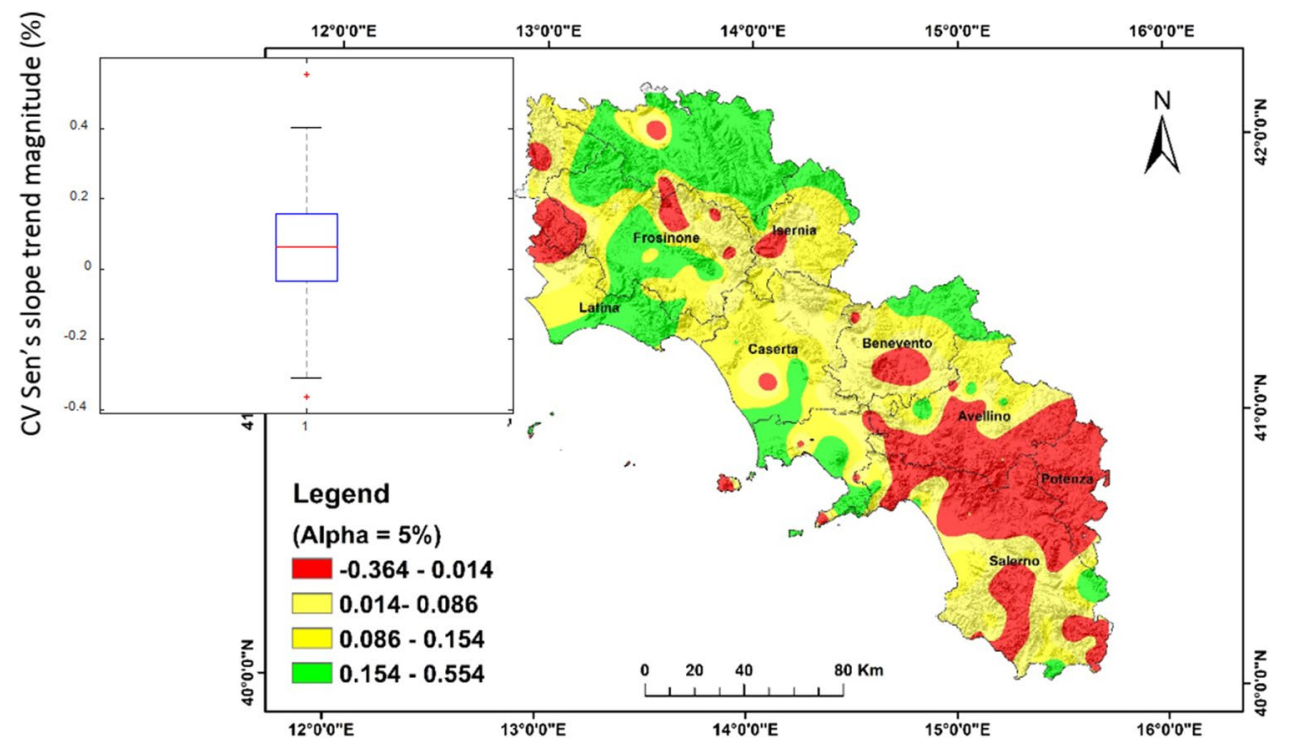

and statistical homogeneity. Given the small number of this subset of rain gauge stations, the focus was only set on the temporal CV variability and no spatial features were derived. The list of the subset of stations, along with the results of the MMK test, is illustrated in Table 2 (significance level $\alpha=$ $5 \%$ ). In addition, the Pettitt test (Pettitt 1979) indicates that there is no breakpoint at any station of the subset studied stations. A summary is furthermore represented in Table 3 (significance level $\alpha=5 \%$ ).

In the period 1918-2015, the general tendency is still set on a large percentage of stations, about $64 \%$, for which a significant trend in the $\mathrm{CV}$ temporal pattern was detected. Additionally, the trend is also in this period positive for the largest percentage of stations, about $60 \%$. Such tendency appeared overall coherent with the results reported in Table 1 for the larger set of 163 stations, where the percentage of stations showing a significant and positive CV trend was only $17 \%$ larger. For what concerns the slope of the $\mathrm{CV}$, an average value of $0.035 \%$ was found in the period 1918-2015, $40 \%$ lower than the average over the period 1918-1999 of about $0.06 \%$. If the qualitative behavior showed coherency in the comparison of the large (163 stations) and the small (30 stations) database, the quantitative assessment of the Sen test, differently from the MMK test, could have been impacted by the restricted number of stations analyzed for the period 1918-2015.

For the same subset of 30 stations, the comparison of the results between the period 1918-1999 ad 1918-2015 provided in Table 3 only shows a very moderate impact of the last fifteen years of observation over the total length of the recording period. The last 15 years saw indeed a very moderate increase in the percentage of the station showing a positive trend (from 57 to $60 \%$ ), a reduction in the percentage of stations showing a significant trend (from 73 to $64 \%$ ), and a moderate reduction of the CV slope (from 0.047 to $0.035 \%$ ). In particular, for what concerns the CV slope, the last 15 years determined a change in the sign of the slope (both positive to negative and negative to positive) only for the $16 \%$ of the analyzed stations (gray cells in Table 2 ).

\section{Discussion: precipitation annual, intra-annual, and inter-annual variability}

As mentioned in Section 1, in order to depict a general characterization of the long-term climate variability for the investigated region, and according to previous studies reported by the relevant literature, it was essential to comment on the observed results about the inter-annual variability in the light of the previous findings reported by the same authors about the annual precipitation regime and the intra-annual precipitation variability for the same area.

In Longobardi and Villani (2010), a study about longterm changes in annual precipitation was performed for the same database and the same region used for the current study (163 stations for the period 1918-1999). It was found that, over the whole region, the trend in annual precipitation appears predominantly negative but that the significance of the changes only holds for a very small number of the total rain gauge stations, about $9 \%$ in the case of negative trend and $27 \%$ in the case of positive trends. Later, in Longobardi et al. (2016), the intra-annual variability of the precipitation regime, summarized by the PCI index, was studied for a larger database and a larger region which includes however the area used for the current study. It was found that, for the specific region, the trend in intra-annual precipitation variability is predominantly negative but that the significance of 
Table 2 Mann-Kendall test and Sen test results for the subset of 30 gauged stations ( $\alpha$ $=5 \%)$. Comparison between the periods 1918-1999 and 1918-2015. Gray cells indicate the rain gauge stations for which a change in the sign of the trend was detected

\begin{tabular}{|c|c|c|c|c|c|c|}
\hline & \multicolumn{2}{|l|}{ Significance } & \multicolumn{2}{|l|}{ Sign } & \multicolumn{2}{|l|}{ Slope (\%) } \\
\hline & 1918-1999 & 1918-2015 & 1918-1999 & $1918-2015$ & 1918-1999 & 1918-2015 \\
\hline Agerola (Fraz. S. Lazzaro) & Trend & No_trend & Positive & Positive & 0.222 & 0.134 \\
\hline Albanella (Ponte Barizzo) & Trend & No_trend & Positive & Negative & 0.085 & -0.015 \\
\hline Benevento (Genio Civile) & Trend & No_trend & Negative & Positive & -0.155 & 0.008 \\
\hline Capua & Trend & Trend & Positive & Positive & 0.241 & 0.224 \\
\hline Caserta (Genio Civile) & Trend & Trend & Positive & Positive & 0.064 & 0.063 \\
\hline Cassano Irpino & Trend & Trend & Negative & Negative & -0.246 & -0.23 \\
\hline Cava Dei Tirreni & No_Trend & Trend & Negative & Negative & -0.063 & -0.06 \\
\hline Ercolano (Oss. Vesuviano) & Trend & No_trend & Positive & Positive & 0.319 & 0.086 \\
\hline Forino & Trend & Trend & Negative & Negative & -0.127 & -0.096 \\
\hline Gragnano & Trend & Trend & Positive & Positive & 0.3 & 0.268 \\
\hline Grazzanise & No_Trend & Trend & Negative & Negative & -0.066 & -0.069 \\
\hline Luogosano & No_Trend & No_trend & Negative & Positive & -0.122 & 0.023 \\
\hline Maiori & Trend & Trend & Negative & Negative & -0.073 & -0.068 \\
\hline Massalubrense (Turro) & Trend & Trend & Negative & Negative & -0.085 & -0.126 \\
\hline Mercato S.Severino & Trend & Trend & Negative & Negative & -0.114 & -0.091 \\
\hline Morcone & Trend & Trend & Positive & Positive & 0.118 & 0.098 \\
\hline Morigerati & Trend & Trend & Positive & Positive & 0.058 & 0.093 \\
\hline Napoli (Capodimonte) & No_Trend & No_trend & Negative & Negative & -0.055 & -0.016 \\
\hline Paduli & No_Trend & No_trend & Positive & Positive & 0.047 & 0.057 \\
\hline Pellezzano & Trend & Trend & Negative & Negative & -0.049 & -0.044 \\
\hline Positano & Trend & Trend & Positive & Positive & 0.28 & 0.198 \\
\hline Pozzuoli & Trend & No_trend & Positive & Negative & 0.192 & -0.023 \\
\hline Ravello & No_Trend & Trend & Positive & Positive & 0.065 & 0.138 \\
\hline Roccadaspide & No_Trend & Trend & Positive & Positive & 0.043 & 0.123 \\
\hline Rofrano & Trend & Trend & Positive & Positive & 0.132 & 0.163 \\
\hline S. Angelo D'alife & No_Trend & No_trend & Positive & Positive & 0.022 & 0.05 \\
\hline Sala Consilina & Trend & Trend & Positive & Positive & 0.173 & 0.166 \\
\hline Salerno (Genio Civile) * & Trend & Trend & Negative & Negative & -0.047 & -0.05 \\
\hline Torraca & Trend & No_trend & Negative & Positive & -0.061 & 0.011 \\
\hline Tramonti (Chiunzi) & Trend & No_trend & Positive & Positive & 0.2 & 0.024 \\
\hline Average & & & & & 0.043 & 0.035 \\
\hline
\end{tabular}

Table 3 Summary of the Mann-Kendall test results for the subset of 30 gauged stations $(\alpha=5 \%)$. Comparison between the periods 1918 1999 and 1918-2015

\begin{tabular}{lll}
\hline & $\begin{array}{l}1918-1999 \\
\%\end{array}$ & $\begin{array}{l}\text { 1918-015 } \\
\end{array}$ \\
\hline Stations with significant trend & 73 & 64 \\
Stations with not significant trend & 27 & 34 \\
Stations with positive trend & 57 & 60 \\
Stations with negative trend & 43 & 40 \\
\hline
\end{tabular}

the changes only holds for a very small number of the total rain gauge stations of about $11 \%$.

The overall findings of the previous studies over the region under analysis delineated a general, but not markedly significant, tendency toward a reduction in total precipitation and a general, but again not markedly significant, tendency toward a more uniform distribution of the total precipitation during the year (reduction in climate seasonality).

Figure 6 compares the spatial distribution of mean annual precipitation, precipitation concentration index, and average coefficient of variation. The mean annual precipitation spatial pattern is strongly influenced by the orography of the region, with the tallest relieves running north-west toward the south-east, where the largest values of MAP, between 1500 and $2000 \mathrm{~mm}$, can be found. Similarly, the average PCI spatial distribution is markedly affected by the orography and the distance from the coastline. Coastal areas are featured by the largest PCI values, of about 13 to 16, opposite to the inland areas where the average PCI approaches values up to 11 . While a strong connection appears between the MAP and PCI spatial distribution over the region, the CV spatial distribution seems only partially affected by the latter 


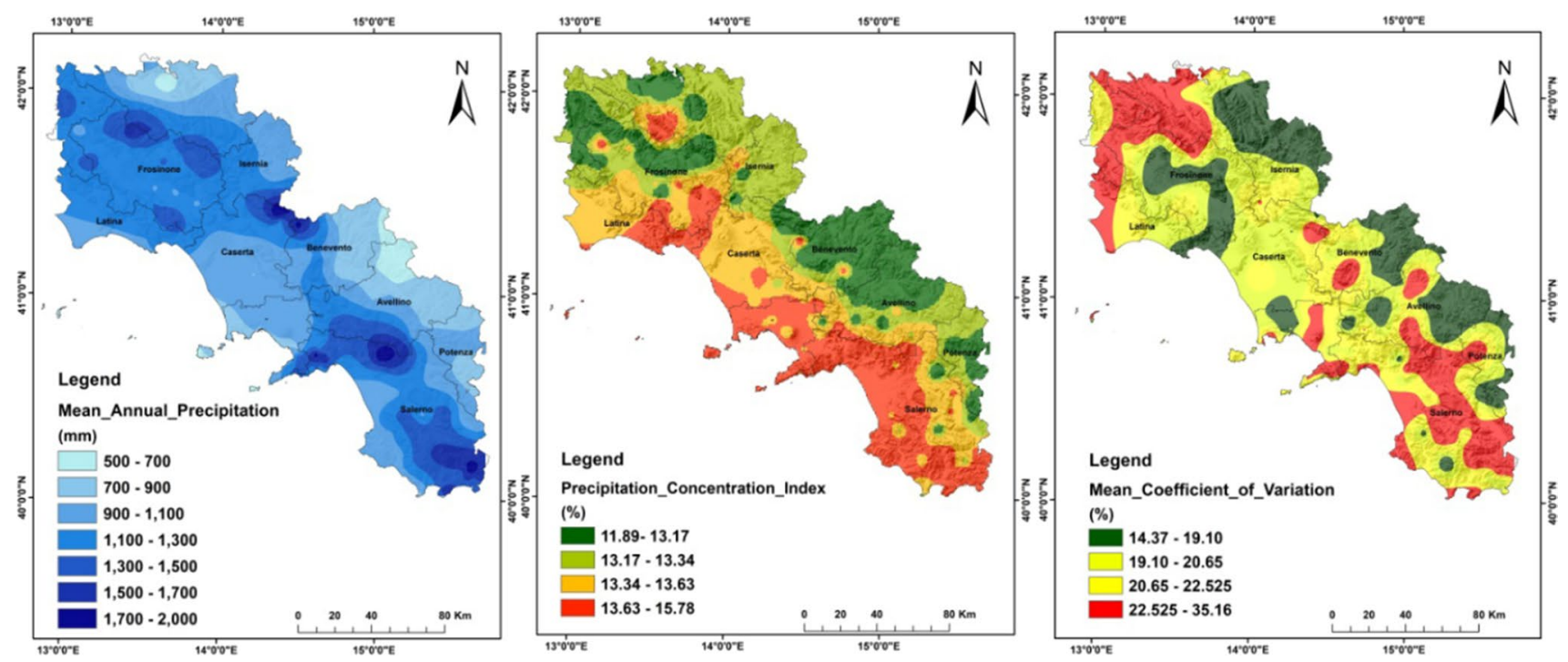

Fig. 6 Spatial distribution of mean annual precipitation (left panel), precipitation concentration index (middle panel), and precipitation coefficient of variation (right panel)

features. Indeed, larger CV values appear associated with the largest MAP values and the largest PCI values and the reverse, but the relationship among these variables is poor. This condition is also illustrated in Fig. 7 where the red dots represent the observation and a polynomial surface has been fitted to them. The goodness-of-fit is quite poor $\left(R^{2}=0.20\right)$ but, again, larger $C V$ values appear associated with large MAP and PCI values.

The specific findings reported for the region under investigation appeared actually in contrast with the main results illustrated by the relevant literature. Although some edge effects may influence the spatial distribution of the observed quantities due to the interpolation issues, the main motivation is probably represented by a limitation of the case study that presents, on the whole, some rather characteristics of climatic homogeneity. A spatial extension of the rain gauge stations database is foreseen to more in detail investigate these particular features.

\section{Conclusions}

In order to depict a general characterization of the longterm climate variability for the Campania region, located in the Mediterranean basin, an analysis of the precipitation coefficient of variation $\mathrm{CV}$, assumed as an index of inter-annual climate variability, was performed over the period 1918-2015 and compared with the results of a previous investigation about the annual precipitation regime and the intra-annual precipitation variability of the same region. Understanding the inter-annual precipitation variability from long-term historical precipitation variability

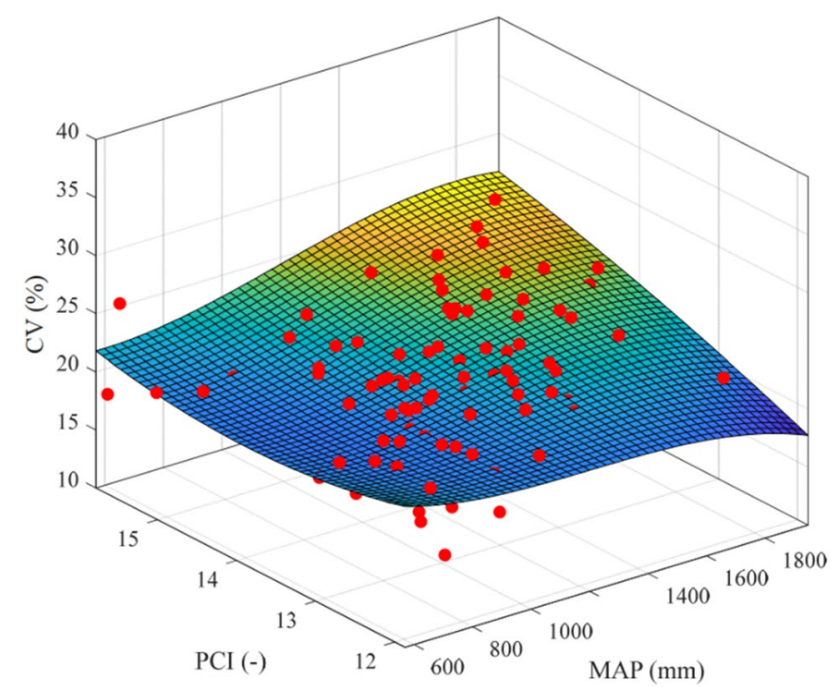

Fig. 7 Relationship between MAP, PCI, and CV for the studied region

is necessary to plan mitigation strategies to face future climate change impacts in specific regions. In particular, quantification of the inter-annual precipitation variability is essential for more realistic modeling of water resources availability under climate change scenario, which in turn results in a more effective quantification of socioeconomics impact of planned complex water resources management tools.

The results of the current study can be summarized as in the following:

1. For what concerns the average $\mathrm{CV}$ characterization and spatial pattern, the findings illustrated a generalized con- 
ditions of statistically significant ( $73 \%$ of total stations) increase ( $72 \%$ of total stations) of inter-annual variability almost over the whole analyzed area, where a very moderate spatial consistency was however detected.

2. For what concerns the magnitude of the changes, the results of the analysis reported about a rather moderate intensity of the detected changes, with minimum and maximum CV patterns slope, expressed as the percentage of annual increase or decrease in $\mathrm{CV}$ over the whole observations recording, which amount respectively to $-0.36 \%$ and $0.55 \%$. Similar to the average CV characterization, no strong spatial consistency was detected, but rain gauge stations featured by the largest average inter-annual variability seemed to be the less affected by temporal changes.

3. The effect of the last 15 years of data, from 2000 to 2015, was only studied on a subset of stations because of data availability and statistical homogeneity. The comparative analysis of the statistical tests results for the period 1918-1999 and 1918-2015 showed, beyond the same general tendency (significant positive trends for the largest percentage of stations), that some quantitative difference between the two observed periods exists but that such difference appeared very moderate.

4. The relationship between average precipitation, intraannual precipitation variability, and inter-annual precipitation variability was not clearly identified for the studied region, but it was found that larger $\mathrm{CV}$ values appear associated with large MAP and large PCI values.

5. The main message that arises from the comparative analysis of average precipitation, intra-annual precipitation variability, and inter-annual precipitation variability showed how, if the variations in the annual precipitation regime and in the intra-annual precipitation variability are poorly significant (respectively for $9 \%$ and $11 \%$ of total station), changes in inter-annual precipitation variability are strongly marked over the studied region.

The current work has increased the knowledge about the long-term climatological characterization of a specific area. It furthermore has contributed to extending the body of literature relevant to the use of historical observation aimed at the detection of changes in inter-annual variability within the Mediterranean basin, known to be one the most responsive region to climate changes. As a future perspective, an extension to a spatially wider database Longobardi et al. (2016) is foreseen to overcome the climatic homogeneity issue which, in the opinion of the authors, dampened the significance of the link between CV, MAP, and PCI.

Acknowledgements The authors would like to thank the "Centro Funzionale Multirischi della Protezione Civile Regione Campania" for providing the observed precipitation data.
Author contributions A.L. and O.B. contributed to the conceptualization. A.L. and O.B. contributed to data curation and formal analysis. A.L. provided supervision, and A.L. and O.B. wrote the original draft. A.L. and O.B. contributed to the revised manuscript version.

Funding The authors gratefully acknowledge the funding support provided through the Instruction, University, and Research Italian Ministry (MIUR) under the grants 300393FRB17 and 300393FRB18.

Data availability The monthly rainfall data are available at "Centro Funzionale Multirischi di Protezione Civile Regione Campania" (http:// centrofunzionale.regione.campania.it/).

\section{Declarations}

Competing interests The authors declare no competing interests.

Open Access This article is licensed under a Creative Commons Attribution 4.0 International License, which permits use, sharing, adaptation, distribution and reproduction in any medium or format, as long as you give appropriate credit to the original author(s) and the source, provide a link to the Creative Commons licence, and indicate if changes were made. The images or other third party material in this article are included in the article's Creative Commons licence, unless indicated otherwise in a credit line to the material. If material is not included in the article's Creative Commons licence and your intended use is not permitted by statutory regulation or exceeds the permitted use, you will need to obtain permission directly from the copyright holder. To view a copy of this licence, visit http://creativecommons.org/licenses/by/4.0/.

\section{References}

Gamelin FX, Baquet G, Berthoin S, Thevenet D, Nourry C, Nottin S, Bosquet L (2009) Effect of high intensity intermittent training on heart rate variability in prepubescent children. Eur J Appl Physiol 105:731-738. https://doi.org/10.1007/s00421-008-0955-8

Boulariah O, Longobardi A, Meddi M (2017) Hydroclimate temporal variability in a coastal Mediterranean watershed: the Tafna basin, NorthWest Algeria. EGU General Assembly Conference Abstracts 17462

Califano F, Mobilia M, Longobardi A (2015) Heavy rainfall temporal characterization in the peri-urban solofrana river basin, southern Italy. Procedia Eng 119:1129-1138. https://doi.org/10.1016/j. proeng.2015.08.957

Chandniha SK, Meshram SG, Adamowski JF, Meshram C (2017) Trend analysis of precipitation in Jharkhand State, India. Theoret Appl Climatol 130:261-274. https://doi.org/10.1007/s00704-016-1875-x

Conrad V (1941) The variability of precipitation. Monthly Weather Rev 69:5-11. https://doi.org/10.1175/1520-0493(1941)069<0005:TVO $\mathrm{P}>2.0 . \mathrm{CO} ; 2$

Dünkeloh A, Jacobeit J (2003) Circulation dynamics of Mediterranean precipitation variability 1948-98. Int J Climatol: A J Royal Meteorol Soc 23:1843-1866. https://doi.org/10.1002/joc.973

Fatichi S, Ivanov VY, Caporali E (2012) Investigating interannual variability of precipitation at the global scale: is there a connection with seasonality? J climate 25:5512-5523. https://doi. org/10.1175/JCLI-D-11-00356.1

Fattoruso G, Longobardi A, Pizzuti A, Molinara M, Marocco C, de Vito S, Tortorella F, Di Francia G (2017) Evaluation and design of a rain gauge network using a statistical optimization method in a severe hydro-geological hazard prone area. AIP Conference Proc AIP Publishing, 020055. https://doi.org/10.1063/1.4981995 
Gajbhiye S, Meshram C, Mirabbasi R, Sharma S (2016) Trend analysis of rainfall time series for Sindh river basin in India. Theoret Appl Climatol 125:593-608. https://doi.org/10.1007/ s00704-015-1529-4

Giorgi F (2006) Climate change hot-spots. Geophys Res Lett 33. https://doi.org/10.1029/2006GL025734

Giorgi F, Bi X (2005) Regional changes in surface climate interannual variability for the 21 st century from ensembles of global model simulations. Geophys Res Lett 32. https://doi.org/10. 1029/2005GL023002

Giorgi F, Lionello P (2008) Climate change projections for the Mediterranean region. Global Planet Change 63:90-104. https://doi. org/10.1016/j.gloplacha.2007.09.005

Hamed KH, Rao AR (1998) A modified Mann-Kendall trend test for autocorrelated data. J hydrol 204:182-196. https://doi.org/10. 1016/S0022-1694(97)00125-X

Hamilton LC, Keim BD (2009) Regional variation in perceptions about climate change. Int J Climatol: A J Royal Meteorol Soc 29:2348-2352. https://doi.org/10.1002/joc. 1930

He C, Li T (2019) Does global warming amplify interannual climate variability? Climate Dynamics 52:2667-2684. https://doi.org/ 10.1007/s00382-018-4286-0

He M, Gautam M (2016) Variability and trends in precipitation, temperature and drought indices in the State of California. Hydrology 3:14. https://doi.org/10.3390/hydrology3020014

Kendall, M. G. 1948. Rank correlation methods.

IPCC. Climate Change (2014) Synthesis Report. Contribution of Working Groups I, II and III to the Fifth Assessment Report of the Intergovernmental Panel on Climate Change [Core Writing Team, R.K. Pachauri and L.A. Meyer (eds.)]. IPCC, Geneva, Switzerland, $151 \mathrm{pp}$

Lazoglou G, Anagnostopoulou C, Tolika K, Kolyva-Machera F (2019) A review of statistical methods to analyze extreme precipitation and temperature events in the Mediterranean region. Theoret Appl Climatol 136:99-117. https://doi.org/10.1007/ s00704-018-2467-8

Longobardi A, Van Loon AF (2018) Assessing baseflow index vulnerability to variation in dry spell length for a range of catchment and climate properties. Hydrological Processes 32(16):2496-2509

Longobardi A, Villani P (2010) Trend analysis of annual and seasonal rainfall time series in the Mediterranean area. Int J Climatol 30:1538-1546. https://doi.org/10.1002/joc.2001

Longobardi A, Mautone M (2015) Trend analysis of annual and seasonal air temperature time series in southern Italy. Engineering Geology for Society and Territory-Volume 3. Springer. https:// doi.org/10.1007/978-3-319-09054-2_102

Longobardi A, Buttafuoco G, Caloiero T, Coscarelli R (2016) Spatial and temporal distribution of precipitation in a Mediterranean area (southern Italy). Environ Earth Sci 75:189. https://doi.org/ 10.1007/s12665-015-5045-8

Longobardi A, Boulariah O, Villani P (2021) Assessment of centennial (1918-2019) drought features in the Campania region by historical in situ measurements (southern Italy). Nat Hazards Earth Syst Sci 21(8):2181-2196. https://doi.org/10.5194/ nhess-21-2181-2021

Luterbacher J, Xoplaki E, Casty C, Wanner H, Pauling A, Küttel M, Brönnimann S, Fischer E, Fleitmann D, Gonzalez-Rouco FJ (2006) Mediterranean climate variability over the last centuries: a review. Dev Earth Environ Sci 4:27-148. https://doi.org/10. 1016/S1571-9197(06)80004-2

Mann HB (1945) Nonparametric tests against trend. Econometrica: J Econ Soc:245-259. https://doi.org/10.2307/1907187

Marini G, Fontana N, Mishra AK (2019) Investigating drought in Apulia region, Italy using SPI and RDI. Theoret Appl Climatol 137(1-2):383-397
Martino GD, Fontana N, Marini G, Singh VP (2012) Variability and trend in seasonal precipitation in the continental United States. J Hydrologic Eng 18:630-640. https://doi.org/10.1061/(ASCE) HE.1943-5584.0000677

Meddi MM, Assani AA, Meddi H (2010) Temporal variability of annual rainfall in the Macta and Tafna catchments, Northwestern Algeria. Water Resour Manag 24:3817-3833. https://doi. org/10.1007/s11269-010-9635-7

Nicholls N, Wong K (1990) Dependence of rainfall variability on mean rainfall, latitude, and the Southern Oscillation. J Climate 3:163-170. https://doi.org/10.1175/1520-0442(1990)003<0163:DORVOM>2.0 .CO;2

Oliver JE (1980) Monthly precipitation distribution: a comparative index. Professional Geographer 32:300-309. https://doi.org/10. 1111/j.0033-0124.1980.00300.x

Pendergrass AG, Knutti R, Lehner F, Deser C, Sanderson BM (2017) Precipitation variability increases in a warmer climate. Scientific Reports 7:17966. https://doi.org/10.1038/ s41598-017-17966-y

Pettitt AN (1979) A non-parametric approach to the change-point problem. Appl Stat Leics, England 28(2):126-135

Pierleoni A, Camici S, Brocca L, Moramarco T, Casadei S (2014) Climate change and decision support systems for water resource management. Procedia Eng 70:1324-1333

Preziosi E, Del Bon A, Romano E, Petrangeli AB, Casadei S (2013) Vulnerability to drought of a complex water supply system. The Upper Tiber Basin Case Study (Central Italy). Water Resour Manag 27(13):4655-4678

Ramos M, Martínez-Casasnovas J (2006) Trends in precipitation concentration and extremes in the Mediterranean PenedesAnoia region, NE Spain. Climatic Change 74:457-474. https:// doi.org/10.1007/s10584-006-3458-9

Rodriguez-Puebla C, Encinas A, Nieto S, Garmendia J (1998) Spatial and temporal patterns of annual precipitation variability over the Iberian Peninsula. Int J Climatol: A J Royal Meteorol Soc 18:299-316. https://doi.org/10.1002/(SICI)10970088(19980315)18:3\%3C299::AID-JOC247\%3E3.0.CO;2-L

Ronco P, Zennaro F, Torresan S, Critto A, Santini M, Trabucco A, Zollo AL, Galluccio G, Marcomini A (2017) A risk assessment framework for irrigated agriculture under climate change. Advances Water Resour 110:562-578

Santos LDC, José JV, Alves DS, Nitsche PR, Reis EFD, Bender FD (2017) Space-time variability of evapotranspiration and precipitation in the State of Paraná, Brazil. Revista Ambiente \& Água 12:743-759. https://doi.org/10.4136/ambi-agua.2057

Sen PK (1968) Estimates of the regression coefficient based on Kendall's tau. J Am Statist Assoc 63:1379-1389

Sohoulande djebou DC, Singh VP (2016) Impact of climate change on precipitation patterns: a comparative approach. Int J Climatol 36:3588-3606. https://doi.org/10.1002/joc.4578

Tallaksen LM, Van Lanen HAJ (2004) Hydrological drought: processes and estimation methods for streamflow and groundwater. In: Developments in Water Science, vol 48. Elsevier Science B.V, Amsterdam

Theil H (1950) A rank-invariant method of linear and polynominal regression analysis (parts 1-3). Ned Akad. Wetensch. Proc. Ser. A,. 1397-1412.

Wmo (1989) Calculation of monthly and annual 30-year standard normals: WCDP-No. 10. WMO-TD/No. 341. World Meteorological Organization, Geneva

Yue S, Wang C (2004) The Mann-Kendall test modified by effective sample size to detect trend in serially correlated hydrological series. Water Resour Manag 18:201-218. https://doi.org/10. 1023/B:WARM.0000043140.61082.60

Publisher's note Springer Nature remains neutral with regard to jurisdictional claims in published maps and institutional affiliations. 